ORIGINAL ARTICLE

\title{
Effects of Nigella sativa and amino acids on growth performance and haematological parameters of broiler
}

\author{
M.S.U. Akon ${ }^{1}$, M.R. Amin 1 , M.T. Hussan², R. Akhter ${ }^{4}$, M.L. Mollah ${ }^{3 *}$
}

${ }^{1}$ Department of Physiology and Pharmacology, ${ }^{2}$ Department of Anatomy and Histology, ${ }^{3}$ Department of Medicine, Surgery and Obstetrics, Faculty of Animal Science and Veterinary Medicine, Patuakhali

Science and Technology University, Babugonj, Barisal-8210, Bangladesh, ${ }^{4}$ Department of Pharmacology and Toxicology, Faculty of Animal Science and Veterinary Medicine, Sher-e-Bangla Agricultural University, Sher-e-Bangla Nagar-1207, Bangladesh

\begin{abstract}
Background: Recently, the use of antibiotic growth promoters has been banned in many countries due to cross-resistance among pathogens and residues in tissues, which led to search for the alternative feed additives in animal production. The aim of this study was to investigate the effects of "Kalo jeera" (Nigella sativa) powder and amino acids supplementation on the growth of broiler chicks and their blood parameters.

Methods: A total of 100 day-old $\left(\mathrm{Cobb}^{\circledR} 500\right)$ chicks were randomly divided into four groups such as $\mathrm{T}_{0}, \mathrm{~T}_{1}, \mathrm{~T}_{2}, \mathrm{~T}_{3}$, and each group contained 25 chicks. The group $\mathrm{T}_{0}$ was used as control and groups $T_{1}, T_{2}$ and $T_{3}$ were treated group. Chicks of control group were fed with only basal diet and no supplements were supplied, and chicks of treatment group including $T_{1}, T_{2}$ and $T_{3}$ were supplemented with amino acids, Nigella sativa powder and combination of Nigella sativa and amino acids, respectively. Body weight was recorded on $7^{\text {th }}, 14^{\text {th }}, 21^{\text {th }}, 28^{\text {th }}$ and $35^{\text {th }}$ day of age. Haematological tests were performed at $15^{\text {th }}, 25^{\text {th }}$ and $35^{\text {th }}$ day of age.

Results: The results showed that net weight gain and feed conversion ratio were improved in the treated groups than that of the control group. Among the treated groups, the significant level of improvement was achieved in the $T_{3}$ group followed by $T_{1}$ and then $T_{2}$. Total erythrocyte count, packed cell volume and haemoglobin concentration were significant $(\mathrm{p}<0.01)$ in the treated groups as compared to control.

Conclusions: The results suggest that better growth performance could be achieved in broilers supplemented with Nigella sativa and amino acids in combination and those can be used as growth promoters.
\end{abstract}

Key words: Nigella sativa, Amino acid, Broiler, Growth performance, Blood parameters.

Copyright ( 2019 Bangladesh Society for Veterinary Medicine. This is an open access article under the CC BY license (http://creativecommons.org/licenses/by/4.0/), which permits unrestricted use, distribution, and reproduction in any medium, provided the original author and source are credited. 


\section{Introduction}

Poultry farming is one of the most successful and rapidly growing industries in Bangladesh which provides not only high quality protein in the form of meat and eggs but also generates employments. The use of antibiotics as a principal growth promoter in poultry feed often resulted in the incidence of cross resistance among pathogens and also a source of residues in animal body tissues (Schwarz et al., 2001). Consequently, the European Union including many other countries have banned the use of antibiotics as a growth promoter in animal feeds (Toghyani et al., 2010). Ultimately, the use of antibiotics in the poultry feed was reduced. These led to a search for alternative natural growth promoters in animal production. Herbal medicinal plants and their extracts have been used as feed supplements since ancient times. Nigella sativa (Kalanji or black cumin) under the family of Ranunculaceae is utilized as a medicinal plant, herb and spice worldwide (Akhtar et al., 2003). The Nigella sativa contains about 20.7 to $26.7 \%$ crude protein, 35.6 to $42.1 \%$ fixed oil and 0.5 $1.6 \%$ volatile oil (AL-Gaby, 1998). Nigella sativa has been extensively studied for its active constituents in which oils are the principle components (Tawfeek et al., 2006; AL-Douri et al., 2010; Nasir and Grashorn, 2009, 2010; Khan et al., 2012). The active compositions of Nigella seed are the volatile oils thymoquinoline and dithymoquinoline, both of which have antitumor properties (Abu-AL-Basal, 2011). In addition, Nigella sativa have been reported to have many biological properties including an antibacterial activity (Hanafy and Hatem, 1991; Mouhajir et al., 1999; Nair et al., 2005), antioxidant (Tawfeek et al., 2006), antiparasitic (Mahmoud et al., 2002), antidiarrheal (Gilani et al., 2004), antidiabetic (Meral et al., 2001), diuretic (Zaoui et al., 2000), and protective effect against liver damage (Mahmoud et al., 2002). It has been considered one of the greatest forms of healing medicine available, especially in Middle East and Asia, as it was mentioned that black seed is the remedy for all diseases except death in one of the prophetic hadith. It is also recommended for use on regular basis in "Tibb-e-Nabwi" (prophetic medicine) (Al-Bukhari, 1976). The commercial farming is becoming challenging for obtaining the desired weight without the use of antibiotics as growth promoters; therefore natural products capable of meeting the challenge are desired. Different studies on the effect of Nigella sativa seed on broiler performance have been carried out. Improved average daily weight gain and better feed conversion ratio (FCR) in broilers was achieved with fed $1 \%$ Nigella sativa seed in broiler diet (Guler et al., 2006; Durrani et al., 2007; AL-Beitawi et al., 2009) in different countries such as Turkey, Pakistan, Jordan. ElGhammry et al. (2002) and Hassan et al. (2004) reported an increased body weight by incorporating grounded Nigella sativa seed in broiler feed. Heat stressed broilers fed black cumin oil $(0.5,1 \%)$, seeds $(1,2 \%)$ or meal $(10$, $20 \%$ ) in feed showed better results than the control group. Significant improvement was observed regarding FCR, crude protein conversion (CPC), calorie conversion ratio (CCR) and feed consumption of the birds (Hermes et al., 2009). Some authors report that Nigella seed has immuno-stimulant effects, thus maintaining good animal health (Afifi, 2001; Mahmoud et al., 2002; AL-Beitawi and El-Ghousein, 2008). Hermes et al. (2009) also reported that Nigella sativa oil at 0.5 and $1 \%$ significantly increased white blood cells (WBCs) and packed cell volume (PCV) compared to the control, while decreasing triglycerides, and alanine aminotransferase (ALT). To the best our knowledge, the report on the effects of Nigella sativa along with amino acids on growth performance, and haematological values of broiler chickens in Bangladesh, particularly for coastal area of southern districts is still absent. Therefore, the present study was designed to investigate the effects of dietary supplementation of Nigella sativa (with and without amino acid supplementation) as an alternative growth promoter on growth performance and blood parameters of broilers raised under coastal climate condition of Bangladesh.

\section{Material and Methods}

This study was conducted at a poultry farm located at Uzirpur, Barishal Sadar, Barishal. A total of 100 one-day-old chicks (Cobb-500), 
"Kalo jeera" (Nigella sativa) seeds (from local market) and amino acids (Availa Z/M, Renata Ltd.) were purchased. After washing and drying "kalo jeera" seeds were crushed into powder. Broiler chicks $(n=100)$ were randomly divided into four groups, namely $\mathrm{T}_{0}$ (control group), $\mathrm{T}_{1}$, $\mathrm{T}_{2}$, and $\mathrm{T}_{3}$ (treatment groups), and each group contained 25 chicks. Chicks of group $\mathrm{T}_{0}$ were fed with basal diet only and no "kalo jeera" and amino acids supplements were supplied. Besides basal diet chicks of treatment groups $T_{1}, T_{2}$, and $\mathrm{T}_{3}$ were supplemented with amino acid $(1 \%$ in drinking water), kalo jeera ( $1 \%$ in drinking water), and both amino acid and "kalo jeera" (1\% in drinking water), respectively. Chicks of both control and treatment groups were monitored closely for 35 days and following parameters were studied.

\section{Body weight and FCR}

The body weight of each bird was measured using a balance on a weekly intervals until 35 days and feed conversion ratio (FCR) was measured at the end.

\section{Blood collection}

Whole blood samples were collected with anticoagulant (4\% sodium citrate) from wing vein of chicken of both control and treated groups at 15 th, $25^{\text {th }}$ and 35th day. Total erythrocyte count (TEC), hemoglobin ( $\mathrm{Hb})$ estimation and determination of packed cell volume (PCV) were conducted.

\section{Determination of total erythrocyte count (TEC)}

For erythrocyte count, dry clean red pipette was dipped into the blood and 0.5 mark blood was drawn into the pipette. Then the tip of the pipette was cleaned by cotton and immediately placed into Hayem's solution and was filled upto 101 marks. The pipette was agitated vigorously by an electric shaker for proper mixing. The unit was expressed in millions per $\mathrm{mm}^{3}$ of blood.

\section{Estimation of haemoglobin (Hb)}

$0.1 \mathrm{~N}$ Hydrochloric acid (HCL) was taken in the graduated diluting tube upto 2 mark with the help of a dropper. A $0.02 \mathrm{ml}$ of blood was added directly into the diluting fluid by Sahli pipette.
Distilled water was added drop by drop and stirred unit the color of the content matches to that of the standard color of the comparator. The haemoglobin $(\mathrm{Hb})$ was recorded within 10 minutes and was expressed in gm\%.

\section{Determination of packed cell volume (PCV)}

After completion of ESR recording the Wintrobe's tubes were placed in the centrifuge machine and centrifuged at $3000 \mathrm{rpm}$ for 30 minutes. Then the hematocrit of PCV was recorded. The percent volume occupied by the hematocrit was calculated by using the following formula.

$$
\text { PCV\% }=\frac{\text { Height of the red cell volume in } \mathrm{cm}}{\text { Height of total blood in } \mathrm{cm}} \times 100
$$

\section{Statistical analysis}

The data were recorded in excel sheet and were analysed statistically among the treatment and groups of chicken by the analysis of variance (ANOVA) technique in completely randomized design by using SAS statistics data editor. Significantly different means among treatments were separated as per the standard method of Duncan at $5 \%$ level of probability $(\mathrm{P}<0.05)$.

\section{Results and Discussion}

For commercial purpose, broilers are usually reared for 4 to 5 weeks and during this time body weight is increased with the age of birds. In our study, body weights were similar at the day 7 within both control and treated groups (Fig. 1). At day 14 , body weights were increased in the group $\mathrm{T}^{1}$ and $\mathrm{T}^{3}$ but in group $\mathrm{T}^{2}$ was similar to that of control. However, significant differences were observed at 21,28 , and 35 days of age where body weights were increased within all the treated groups. Similar findings were demonstrated by Jahan et al., (2015) showed that body weights were increased within linear pattern at the increase level of dietary Nigella sativa seed meal. Ziad et al., (2008) also supported our findings that broilers feed on $1.5 \%$ crushed Nigella sativa had higher live body weight and net body weight gain in broiler diet. Our results showed that net weight gain (Fig. 2) and FCR (Fig. 2) were improved in the treated groups than that of the control group. Among the treated 


\section{Akon and others}

groups, the significant level of improvement was achieved in the $T_{3}$ group followed by $T_{1}$ and then $\mathrm{T}_{2}$. In terms of FCR, significant improvement was observed in the group treated with both Nigella sativa and amino acids, particularly in the day 28 and 35 (Fig. 2). The improvement of growth performance suggested that Nigella sativa may be associated with highly active components particularly thymoquinone and thymohydroquinone which have robust antioxidant activities. Similar studies were performed by Boka et al. (2014) and found a great enhancement in FCR in broilers supplemented with $0,1,2$, and $3 \%$ Nigella sativa seeds, and the best FCR was recorded in broilers fed on 2\% Nigella sativa. Jahan et al., (2015) showed that FCR was improved using $1.5 \%$ Nigella sativa seeds at the early age of 14 days old of chick. Total erythrocyte counts were significantly greater in quail chicks receiving $1 \%$ and $1.5 \%$ Nigella sativa. Hemoglobin and packed cell volume also were non-significantly higher in the same chicks (Shokrollahi and Sharifi, 2018). In harmony with our current results, Toghyani et al. (2010) suggested that black kumin seeds enhanced total erythrocyte counts, hemoglobin and packed cell volume levels in broilers. In our study, total erythrocyte count (Fig. 3) was not markedly different within both control and treated groups. However, at the age of day 35, significant improvements were noticed. Moreover, packed cell volume (Fig. 4) were increased within treated groups where significantly improved at day 35. By contrast, haemoglobin concentration (Fig. 5) were also significantly $(p<0.01)$ increased in the treated groups as compared to that of control but markedly improved at the day 15 . These results suggest that Nigella sativa may have hematopoietic effect. We observed that the group supplemented with only Nigella sativa has improvement but not at a significant level. However, the group supplemented with amino acid only showed a significant level of improvement. At the same time, the group supplemented with both Nigella sativa and amino acid has improvement which is above the total of both supplementations that may be due to their synergistic effect.

It may be concluded that supplementation of Nigella sativa (Kalo jeera) and amino acid (Availa $\mathrm{Z} / \mathrm{M}^{\circledR}$ ) with drinking water may be used for economical and efficient production of broilers.

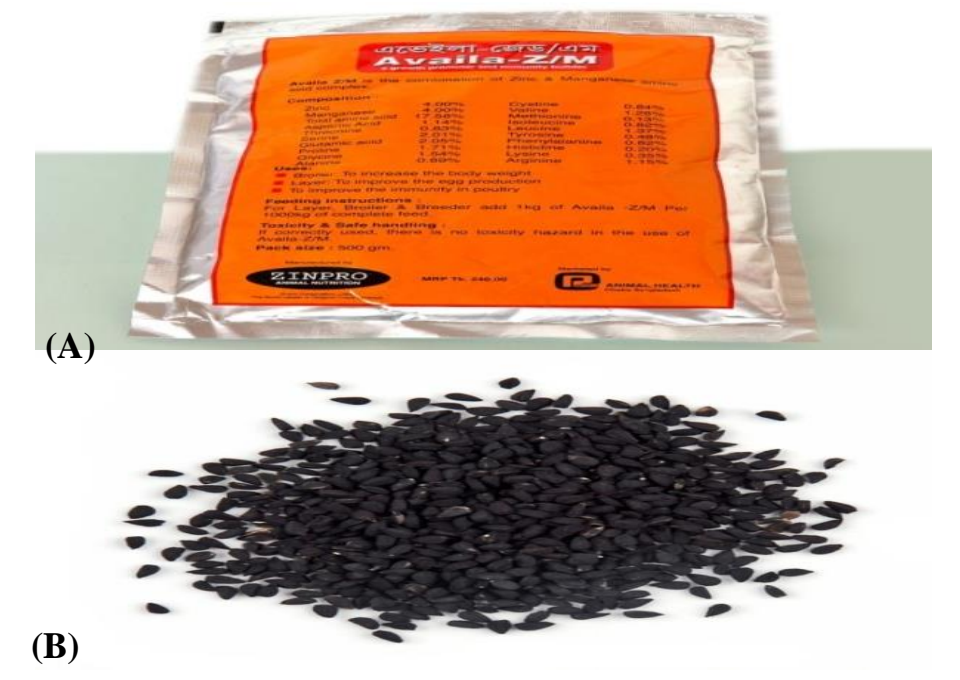

Figure 1: (A) Amino acid (Availa $\mathrm{Z} / \mathrm{M}^{\circledR}$ ) and (B) Nigella sativa (kalo jeera). 
Growth performance and haematological parameters of broiler

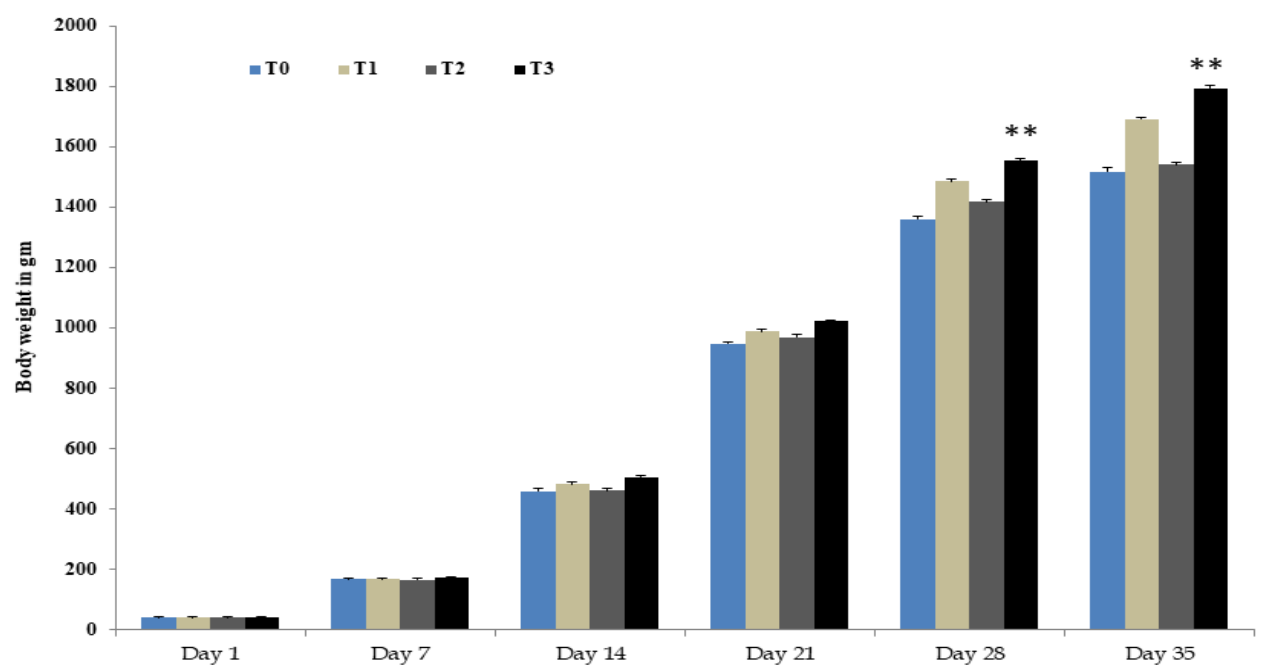

Figure 2: Body weight changes $1^{\text {st }}, 7^{\text {th }}, 14^{\text {th }}, 21^{\text {th }}, 28^{\text {th }}$ and $35^{\text {th }}$ days of treatment with Nigella sativa (kalo jeera) and amino acid (Availa $\mathrm{Z} / \mathrm{M}$ ) in Figure 2 : Body weight changes $1^{\text {st }}, 7^{\mathrm{th}}, 14^{\mathrm{th}}, 21^{\mathrm{h}}, 28^{\mathrm{h}}$ and $35^{\mathrm{t}}$ days of treatment with Nigella sativa (kalo jeera) and amino acid (Availa $\mathrm{Z} / \mathrm{M}$ )
broiler $(\mathrm{n}=25$ in each group). Data are expressed as mean $\pm \mathrm{SD}$ * $\mathrm{p}<0.01$ significantly different for broiler control. Feed with kalo jeera and broiler ( $\mathrm{n}=25$ in each group). Data are expressed as mean $\pm \mathrm{SD}, * \mathrm{p}<0.01$ sig
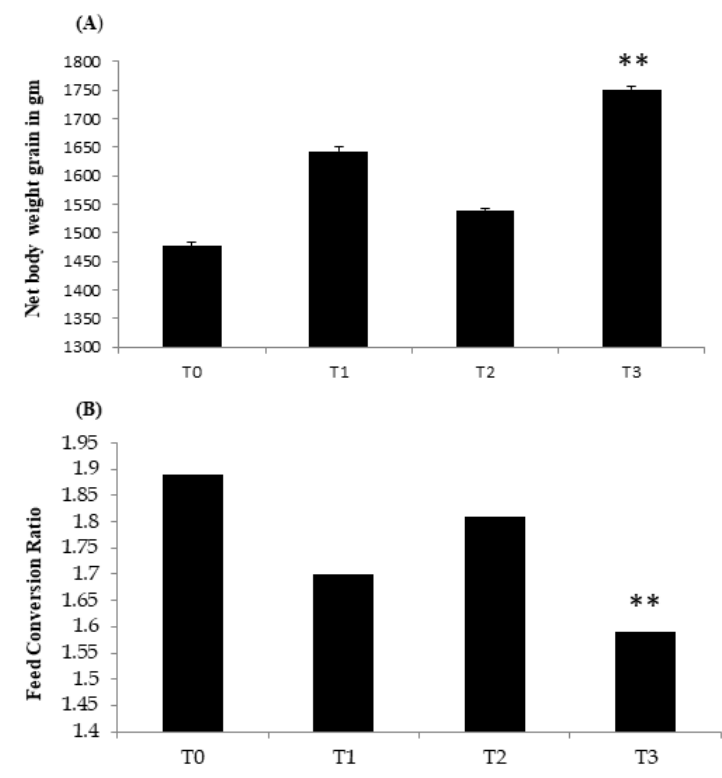

Figure 3: Effects of Nigella sativa (Kalo jeera) and amino acid (Availa $\mathrm{Z}_{\mathrm{M}}{ }^{\sqrt{2}}$ ) on (A) net body weight grain and (B) feed conversion ratio (FCR) of Broilers at $35^{\text {th }}$ Day. 


\section{Akon and others}

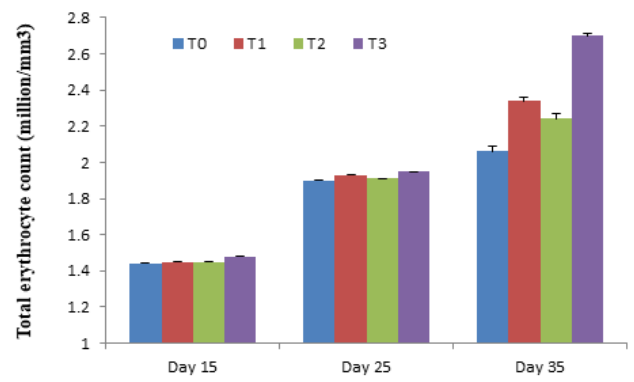

Figure 4: Effects of Nigella sativa (Kalo jeera) and amino acid (Availa Z/M $)$ on $15^{\text {th }}, 25^{\text {th }}$ and $35^{\text {th }}$ day of broiler. Total erythrocyte count (million $/ \mathrm{mm} 3$ ) in different group of broiler. Data are expressed as mean $\pm \mathrm{SD},{ }^{*} \mathrm{p}<0.01$ significantly different for broiler control. Feed with kalo jeera and amino acid, significant at $1 \%$ level of probability $(0.00-0.01)$ of drinking water.

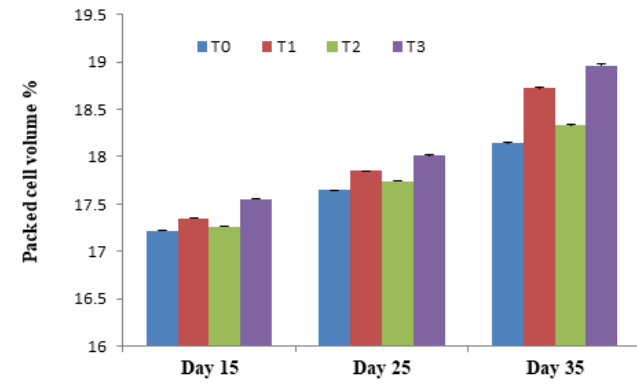
Figure 5: Effects of Nigella sativa (Kalo jeera) and amino acid (Availa $\mathrm{ZM}^{\S}$ ) on $15^{\text {th }}, 25^{\text {th }}$ and $35^{\text {th }}$ day of broiler. The pack
cell volume (PCV) \% in different group of broiler. Data are expressed as mean $\pm \mathrm{SD},{ }^{*} \mathrm{p}<0.01$ significantly different for cell volume $(\mathrm{PCV}) \%$ in different group of broiler. Data are expressed as mean $\pm \mathrm{SD}, * \mathrm{p}<0.01$ significantly different for
broiler control. Feed with kalo jeera and amino acid, significant at $1 \%$ level of probability $(0.00-0.01)$ of drinking water. 


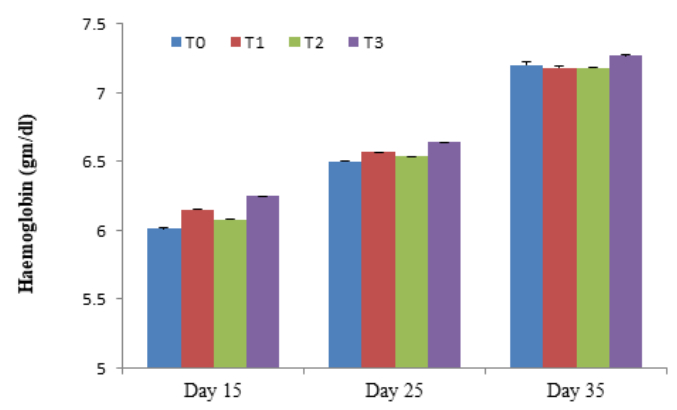

Figure 6: Effects of Nigella sativa (Kalo jeera) and amino acid (Availa Z/M ${ }^{\sqrt{ }}$ ) on $15^{\text {th }}, 25^{\text {th }}$ and $35^{\text {th }}$ day of broiler. The haemoglobin $(\mathrm{Hb})(\mathrm{gm} / \mathrm{dl})$ in different group of broiler. Data are expressed as mean $\pm \mathrm{SD},{ }^{*} \mathrm{p}<0.01$ significantly different for broiler control. Feed with kalo jeera and amino acid, significant at $1 \%$ level of probability $(0.00-0.01)$ of drinking water.

\section{References}

1. Abu-Al-Basal MA. Influence of Nigella sativa fixed oil on some blood parameters and histopathology of skin in Staphylococcal-infected BALB/c Mice. Pakistan Journal of Biological Sciences. 2011; 14 (23):1038-1046.

2. Afifi OS. Effect of different level of freshly crushed Nigella sativa seeds on performance, organ weights and blood constituents of broiler chickens reared under hot climatic conditions. Egyptian Poultry Science Journal. 2001; 21:567-583.

3. Akhtar MS, Nasir Z and Abid AR. Effect of feeding powdered Nigella sativa $\mathrm{L}$. on poultry egg production and their suitability for human consumption. Veterinarski Arhiv. 2003; 73:181-190.

4. AL-Beitawi N and EL-Ghousein SS. Effect of feeding different levels of Nigella sativa seeds (black cumin) on performance, blood constituents and carcass characteristics of broiler chicks. International Journal of Poultry Science. 2008; 7:715-721.
5. Al-Beitawi NA, El-Ghousein SS and Nofal AH. Replacing bacitracin methylene disalicylate by crushed Nigella sativa seeds in broiler rations and its effects on growth, blood constituents and immunity. Livestock Science. 2009; 125:304-307.

6. Al-Bukhari MI. In: Al-Bukhari S, editor. The Collection of Authentic Sayings of Prophet Mohammad (Peace be Upon Him), Division 71 on Medicine. 2nd ed. Hilal Yayinlari, Ankara; 1976.

7. Al-Douri, Asmaa S, Saha Gh and Al-Kazaz A. The Effect of Nigella Sativa oil black seed) on the healing of chemically induced oral ulcer in rabbit Experimental Study. AlRafidain Dental Journal. 2010; 10:151-157.

8. Al-Gaby AMA. Amino acid composition and biological effects of supplementing broad bean and corn proteins with Nigella Sativa (black cumin) cake protein. Nahrung. 1998; 42:290-294.

9. Boka J, Mahdavi AH, Samie AH and Jahanian R. Effect of different levels of black cumin (Nigella sativa L.) on performance, 
intestinal Escherichia coli colonization and jejunal morphology in laying hens. Journal of Animal Physiology and Animal Nutrition. 2014; 98(2):373-383.

10. Durrani FR, Chand N, Zaka K, Sultan A, Khattak FM and Durrani Z. Effect of different levels of feed added black seed (Nigella sativa L.) on the performance of broiler chicks. Pakistan Journal of Biological Sciences. 2007; 10:4164-4167.

11. EL-ghammry AA, EL-Mallah GM and ELYamny AT. The effect of incorporation yeast culture, Nigella sativa seeds and fresh garlic in broiler diets on their performance. Egyptian Poultry Science Journal. 2002; 22:445-459.

12. Gilani AH, Jabeen Q and Khan MAU. A review of medicinal uses and pharmacological activities of Nigella sativa. Pakistan Journal of Biological Sciences. 2004; 7:441-451.

13. Guler T, Dalkilic B, Ertas ON and Ciftci M. The effect of dietary black cumin seeds (Nigella sativa L.) on the performance of broilers. Asian-Australasian Journal of Animal Sciences. 2006; 19:425-430

14. Hanafy MS and Hatem ME. Studies on the antimicrobial activity of Nigella sativa seed black cumin). Journal of Ethnopharmacology. 1991; 34:275-278.

15. Hassan II, Askar AA, Gehan A and ELShourbagy A. Influence of some medicinal plants on performances; physiological and meat quality traits of broiler chicks. Egyptian Poultry Science Journal. 2004; 24:247-266.

16. Hermes IH, Faten AM, Attia KA, Ibrahim and EL-Nesr SS. Effect of dietary nigella sativa L. on productive performance and nutrients utilization of broiler chicks raised under summer conditions of Egypt. Egyptian Poultry Science Journal. 2009; 29:145-172.

17. Islam MT, Selim ASM, Sayed MA, Khatun MA, Siddiqui MN, Alam MS and Hossain MA. Nigella sativa L. supplemented diet decreases egg cholesterol content and suppresses harmful intestinal bacteria in laying hens. Journal of Animal and Feed Sciences. 2011; 20: 587-598.
18. Jahan MS, Khairunnesa M, Afrin S and Ali MS. Dietary black cumin (Nigella sativa) seed meal on growth and meat yield performance of broilers. SAARC Journal of Agriculture. 2015; 13(2):151-160.

19. Khan SH, Ansari J, Haq AU and Abbas G. Black cumin seeds as phytogenic product in broiler diets and its effects on performance, blood constituents, immunity and caecal microbial population. Italian Journal of Animal Science. 2012; e77:438-444.

20. Mahmoud MR, El-Abhar HS and Saleh S. The effect of Nigella sativa oil against the liver damage induced by Schistosoma mansoni infection in mice. Journal of Ethnopharmacology. 2002; 79:1-11.

21. Meral I, Yener Z, Kahraman T and Mert N. Effect of Nigella sativa on glucose concentration, lipid preoxidation, antioxidant defense system and liver damage in experimentally-induced diabetic rabbits. Journal of Veterinary Medicine Series A. 2001; 48:593-599.

22. Mouhajir F, Pedersen JA, Rejdali M and Towers GHN. Antimicrobial thymohydroquinones of Moroccan Nigella sativa seeds detected by electron spin resonance. Pharmaceutical Biology. 1999; 37:391-395.

23. Nair MKM, Vasudevan $P$ and Venkitanarayanan K. Antibacterial effect of black seed on Listeria monocytogenes. Food Control Journal. 2005; 16:395-398.

24. Nasir Z and Grashorn MA. Echinacea: A potential feed and water additive in poultry and swine production. Archiv fur Geflügelkunde. 2009; 73:227-236.

25. Nasir Z and Grashorn MA. Effects of Echinacea purpurea and Nigella sativa supplementation on broiler performance, carcass and meat quality. Journal of Animal and Feed Science. 2010; 19:94-104.

26. Schwarz S, Kehrenberg C and Walsh TR. Use of antimicrobial agents in veterinary medicine and food animal production. International Journal of Antimicrobial Agents. 2001; 17:431-437.

27. Shokrollahi B and Sharifi B. Effect of Nigella sativa seeds on growth performance, 
Growth performance and haematological parameters of broiler

blood parameters, carcass quality and antibody production in Japanese quails. Journal of Livestock Science. 2018; 9:56-64.

28. Tawfeek FKH, Ahmed SM and Kakel SJ. Effect of Nigella sativa oil treatment on the sex organs and sperm characters in rats exposed to hydrogen peroxide. Mesopotamia Journal of Agriculture. 2006; 34(1):2-8.

29. Toghyani M, Toghyani M, Gheisari A, Ghalamkari $G$ and Mohammadrezaei $M$. Growth performance, serum biochemistry and blood hematology of broiler chicks fed different levels of black seed (Nigella sativa) and peppermint (Mentha piperita). Livestock Science. 2010; 129:173-178.

30. Zaoui A, Cherrah Y Lacaille-Dubois, MA, Settaf A, Amarouch H and M Hasar. Diuretic and hypotensive effects of nigella seed in the spontaneously hypertensive rat. Therapie. 2000; 55:379-382.

31. Ziad HM, Abu-Dieyeh, Mohammad S and Abu-Darwish. Effect of feeding powdered Black Cumin Seeds (Nigella sativa) on growth performance of 4-8 week old broilers. Journal of Animal and Veterinary Advances. 2008; 7(3):286-290. 